Abstract 1658 Table 1 Table showing data of all babies assessed for jaundice

\begin{tabular}{llll}
\hline Title & 2019 & 2020 & P value \\
\hline Total Number of babies assessed & 24 & 27 & NS \\
No of babies excluded & 6 & 4 & NS \\
JETSET Babies referred from community & 8 & 12 & NS \\
JETSET Babies referred from A/E & 4 & 3 & NS \\
JETSET Babies without phototherapy & 6 & 6 & NS \\
\hline
\end{tabular}

Abstract 1658 Table 2 Table showing outcome data for JETSET babies who were admitted but no phototherapy

\begin{tabular}{llll}
\hline Title & 2019 & 2020 & P value \\
\hline No of JETSET babies without phototherapy & 6 & 6 & NS \\
Age at Assessment (day) & $6 \pm 3$ & $4 \pm 1$ & 0.16 \\
Percentage weight loss at admission (\%) & $-8 \pm 5$ & $-9 \pm 5$ & 0.72 \\
Maximum bilirubin at assessment( $\mu \mathrm{mol} / \mathrm{l})$ & $299 \pm 43.5$ & $262.3 \pm 41.8$ & $0.03^{*}$ \\
Length of Stay (hrs) & $46.5 \pm 30.5$ & $31.1 \pm 14.5$ & 0.12 \\
\hline
\end{tabular}

this study. The tables below highlight key comparative data in the two cohorts

Compared with 2019, 33\% more babies were referred in for assessment from the community in 2020 (table 1). Jaundiced babies in 2020 were referred earlier, had significantly lower maximum serum bilirubin levels at referral and had reduced length of hospital stay if readmitted (table 2).

Conclusions This study has shown that the introduction of $\mathrm{TcB}$ led to a significantly reduced maximum SBR level at readmission. In addition, we showed a trend towards a streamlined pathway across care settings for healthy jaundiced babies with earlier hospital assessments and improved outcomes for the babies that were admitted to TCU.

\section{PILOT POTENTIAL ORGAN DONOR AUDIT IN THE NEONATAL POPULATION WITH REFERENCE TO THE NATIONAL PAEDIATRIC AND NEONATAL DECEASED DONATION STRATEGY (NHSBT, 2019)}

Trishula Muganthan, Jane Gill. University Hospitals of Leicester

10.1136/archdischild-2021-rcpch.779

Background This retrospective audit over 4 years reviewed all neonatal deaths in a large tertiary neonatal unit (University Hospitals of Leicester NHS Trust).

Objectives To review the potential for organ donation in patients that met the criteria for donation after death confirmed by neurological criteria (DBD) or circulatory death (DCD) in a large tertiary neonatal unit.

Methods The perinatal mortality review database and Badgernet were used to identify all early neonatal (END), late neonatal (LND) and infant deaths (ID) in the time period. Patients were identified that met the NHS Blood and Transplant (NHSBT) eligibility criteria for referral: >36 weeks corrected gestational age (CGA). Badgernet data was used to review cause and modality of death to determine potential for organ donation.
Results There were 125 END, LND and ID identified. 28 patients $(22.4 \%)$ were identified as meeting the above mentioned NHSBT criteria. Out of these 28 patients, 9 patients were potential organ donors (2 potential DBD following neurological death testing and 7 for potential DCD). One patient was referred for DCD, but this did not proceed as the patient continued to gasp for a prolonged period of time.

Conclusions The true potential for neonatal organ donation is not yet known, as identified in the NHSBT strategy. ${ }^{1} \mathrm{~A}$ greater understanding of this potential will allow for better resource management and influence treatment options, thus impacting the transplantation and organ donation process. This pilot audit shows that in a large tertiary neonatal unit, there were approximately 2 potential organ donors per year. A larger potential donor audit is required to establish national numbers and associated resources needed to offer organ donation routinely as part of end of life care for our patient population.

\section{REFERENCE}

1.. UK Paediatric and Neonatal Deceased Donation A Strategic Plan by the Paediatric Subgroup of the National Organ Donation Committee. June 2019.

\section{Paediatric Special Interest Group: British Society of Haematology}

\section{VITAMIN D DEFICIENCY AND SUPPLEMENTATION IN SICKLE CELL DISEASE}

${ }^{1}$ Claire Sharkey, ${ }^{2}$ Emtnan Noreldaam Adam, ${ }^{2}$ Rosena Geoghegan, ${ }^{2}$ Evanne O'Halloran, ${ }^{2}$ Corrina McMahon. ${ }^{1} \mathrm{CH}$ at Crumlin, Dublin, Ireland; ${ }^{2} \mathrm{CHI}$ at Crumlin

\subsection{6/archdischild-2021-rcpch.780}

Background Optimising bone health is of upmost importance in sickle cell disease (SCD) patients given the risk for bony involvement in SCD. These patients are at an increased risk of Vitamin D deficiency given the known higher prevalence of Vitamin D deficiency in those with dark skin from African/ Afro-Caribbean/Asian/Middle Eastern backgrounds. In addition to this, Ireland is located in a northerly latitude and is at risk of suboptimal Vitamin D levels because of reduced sunlight exposure. Osteopenia and osteoporosis has been reported in up to $80 \%$ of SCD patients with other studies indicating a link between Vitamin D deficiency and chronic pain in SCD patients. We wanted to examine Vitamin D levels in our SCD population and establish what supplements our SCD patients were taking, comparing our findings to NICE and Sickle Cell Society and Public Health England (2019) guidelines.

Objectives To identify how many SCD patients in a tertiary unit are Vitamin D deficient and to identify the number of patients currently on a recommended dose of Vitamin D.

Methods Using our database of registered SCD patients, all Vitamin D level results within the past year were reviewed. Members of the haematology team concurrently asked each patient or parent/carer what Vitamin D supplementation, if any, they took regularly when they attended the hospital for review or over telephone clinic across a 4 month period. The patients' charts were then reviewed on a daily basis after clinic and during/after hospital attendances.

Results $93.43 \%$ (313/335) of SCD patients had a vitamin D level taken in the preceding 12 months. The average vitamin $\mathrm{D}$ level was $52.94 \mathrm{nmol} / \mathrm{L}$ (median $=51 \mathrm{nmol} / \mathrm{L}) . \quad 13 \%$ of 